\title{
Neutral Loss of Isocyanic Acid in Peptide CID Spectra: A Novel Diagnostic Marker for Mass Spectrometric Identification of Protein Citrullination
}

\author{
Gang Hao, ${ }^{\mathrm{a}}$ Danchen Wang, Jane Gu, ${ }^{\mathrm{c}}$ Qiuying Shen, ${ }^{\mathrm{b}}$ Steven S. Gross, \\ and Yanming Wang \\ a Department of Pharmacology, Weill Medical College of Cornell University, New York, New York, USA \\ ${ }^{\mathrm{b}}$ Department of Biochemistry and Molecular Biology, Pennsylvania State University, University Park, \\ Pennsylvania, USA \\ ${ }^{c}$ Massoverz Technologies, Albany, New York, USA
}

Protein citrullination is emerging as an important signaling mechanism that modulates a variety of biological processes. This protein modification constitutes only a 1 Da mass shift, and can be readily confused with other common protein modifications that yield an identical mass shift. In an attempt to develop a robust methodology for detection of protein citrullination sites, we analyzed synthetic citrulline-containing peptides by electrospray ionization tandem mass spectrometry. Collision-induced dissociation (CID) spectra revealed abundant neutral loss of $43 \mathrm{Da}$ from citrullinated peptide precursor ions, which was reconciled by elimination of the HNCO moiety (isocyanic acid) from the citrulline ureido group. The elimination occurs readily in multiple charge states of precursor ions and also in $\mathrm{b}$ and y ions. HNCO loss in CID spectra provides a novel diagnostic marker for citrullination, and its utility was demonstrated by the discovery of Arg197 as the specific site of citrullination on nucleophosmin upon peptidylarginine deiminase 4 treatment. (J Am Soc Mass Spectrom 2009, 20, 723-727) (c) 2009 American Society for Mass Spectrometry

$\Upsilon^{i}$ itrullination is a post-translational modification in mammalian cells through which peptidylarginine residues are converted to citrullines (Cit), catalyzed by the peptidylarginine deiminase (PAD) family of enzymes [1,2]. This modification removes the positive charge on arginine (a process termed deimidation), abolishing intra- and intermolecular electrostatic interactions that can modulate the structure and function of proteins. Citrullination is involved in diverse cellular processes including gene regulation, apoptosis, and skin homeostasis [3-5]. Alteration in the level of citrullination is implicated in the pathogenesis of disorders such as multiple sclerosis, rheumatoid arthritis (RA), psoriasis, and Alzheimer's disease [6-9]. In RA, it has been shown that elevated protein citrullination in synovial joints triggers an autoimmune response and results in damage to the joints [10, 11]. An assay for $>$ anti-citrullinated peptide IgG is highly specific for RA in patients and widely used for clinical diagnosis of RA [12, 13].

Notwithstanding the apparent biologic importance of protein citrullination, less than a dozen in vivo citrullinated proteins have been identified, including

Address reprint requests to Dr. Yanming Wang, Pennsylvania State University, 332 South Frear, University Park, PA 16802, USA. E-mail: yuw12@ psu.edu histone proteins $(\mathrm{H} 3, \mathrm{H} 2 \mathrm{~A}, \mathrm{H} 4)$, nucleophosmin, myelin, and keratin [14-19]. While anti-citrulline antibodies can sensitively detect protein citrullination, definition of the exact site of modification can only be established via mass spectrometric approaches. A problem is that the mass shift resulted from conversion of peptidyl arginine to Cit is small ( $+1 \mathrm{Da})$ and isobaric with deamidation on Asn and Gln residues, making it challenging for mass spectrometric detection, especially on low-resolution mass spectrometry instrumentations. A common strategy to enhance confidence in the assignment of a given post-translational modification is to look for hallmark peptide fragmentation products in MS/MS spectra, e.g., phosphate loss from phosphorylated serine or threonine [20, 21]. Recently, tandem mass spectrometry studies of mono- and dimethylarginine containing peptides revealed characteristic neutral losses including monomethylamine, dimethylcarbodiimide, and dimethylamine from the modified arginine side chain [22-24]. In the present study, we explored the gas-phase fragmentation pathways of citrullinated peptides by electrospray-tandem mass spectrometry and discovered a characteristic neutral loss of $43 \mathrm{Da}$ that is reconciled by the release of an isocyanic acid $(\mathrm{HN}=\mathrm{CO})$ moiety from the citrulline ureido group. The dependence of the elimination reaction on precur- 
sor charge states was also investigated. Results suggest that the neutral loss of $\mathrm{HNCO}$ can provide a specific marker for identification of novel citrullinated proteins.

\section{Experimental}

\section{Materials}

Citrullinated reference peptides standard, including $\mathrm{NH}_{2}-$ AA $\{$ Cit $\}$ AA-COOH, $\mathrm{NH}_{2}$-AARAA-COOH, histone $\mathrm{H} 4$ peptide (residues 15-26) $\mathrm{NH}_{2}-\mathrm{AK}\{\mathrm{Cit}\} \mathrm{H}\{\mathrm{Cit}\} \mathrm{KVL}\{\mathrm{Cit}\} \mathrm{DNI}-$ cysteine- $\mathrm{COOH}$, and human NPM peptide (residues 195-202) $\mathrm{NH}_{2}$-SIRDTPAK-COOH were synthesized by Genemed Syn. (San Francisco, CA). Recombinant human His6-nucleophosmin (His6-NPM) and glutathioneS-transferase tagged peptidylarginine deiminase 4 (GST-PAD4) were recombinantly-expressed and purified from E. coli strain BL-21. Sequencing grade trypsin was from Promega (Madison, WI). $\alpha$-Mod-Cit antibody was from Millipore (Billerica, MA). All other reagents were from Sigma-Aldrich (St. Louis, MO).

\section{Mass Spectrometry}

ESI mass spectra were recorded on a Q-Trap triplequadrupole linear ion trap mass spectrometer (Applied Biosystems, Foster City, CA). Reference peptides were diluted to final concentrations of $1 \mathrm{pmol} / \mu \mathrm{L}$ in $50 \%$ acetonitrile (ACN)/0.1\% formic acid (FA) and directly infused to a micro ion spray source at a flow rate of 5 $\mu \mathrm{L} / \mathrm{min}$. All mass spectra were acquired in positive ion mode. The spray voltage was $3800 \mathrm{~V}$, the nebulizing gas was 10 , the curtain gas was 10 , the source temperature was $150{ }^{\circ} \mathrm{C}$, and the declustering voltage was 50 V. CID spectra were acquired in enhanced product-ion mode, at a scan rate of $4000 \mathrm{u} / \mathrm{s}$. Twenty mass spectra were averaged to achieve good ion statistics. The collision energy (CE) was optimized to generate a modest level of fragmentation, i.e., $25 \mathrm{~V}$ for AA $\{\mathrm{Cit}\} \mathrm{AA}$ and AARAA peptides and $45 \mathrm{~V}$ for $\mathrm{AK}\{\mathrm{Cit}\} \mathrm{H}\{\mathrm{Cit}\} \mathrm{KVL}\{\mathrm{Cit}\} \mathrm{DNIC}$, regardless of charge states. $\mathrm{MS}^{3}$ analysis of AA $\{\mathrm{Cit}\} \mathrm{AA}$ neutral loss ion was carried out with an activation time of $100 \mathrm{~ms}$ and an excitation energy of $100 \mathrm{~V}$. The LC-MS analysis of a tryptic digest of nucleophosmin was performed on a homemade capillary flow LC system coupled to the Q Trap mass spectrometer via the micro ion spray interface. All peptides were resolved on a ZORBAX C18 (Agilent Technologies, Santa Clara, CA, USA) $50 \times 300 \mathrm{~mm}$ column at a mobile phase flow rate of $4 \mu \mathrm{L} / \mathrm{min}$. The peptides were eluted using a two- solvent gradient system, where Solvent A comprised water in $0.1 \% \mathrm{FA}$ and Solvent B was ACN in $0.1 \%$ FA. The percentage of Solvent B was increased from 5\% to $50 \%$ in $50 \mathrm{~min}$ and to $80 \%$ from 50 to $60 \mathrm{~min}$. Data dependent CID spectra were acquired on the two most intense precursor ions after each MS scan. The CE value used in the data-dependant acquisition was calculated by the Analyst software using a charge state and $m / z$ dependent equation. The $\mathrm{CE}$ was $42 \mathrm{~V}$ for the singly-charged peptide SI R/Cit\}DTPAK and $28 \mathrm{~V}$ for the doublycharged peptide. The CID spectra were searched against the human NPM sequence using the ProteinPilot program (version 2.01, Applied Biosystems) for peptide identification.

\section{Results and Discussion}

We first studied a small citrullinated peptide, AA $\{\mathrm{Cit}\} \mathrm{AA}$, and compared its fragmentation behavior with the Arg-containing counterpart, AARAA. The resulting CID spectra are shown in Supplemental Figure 1, which can be found in the electronic version of this article. Both peptides were found to be singly-protonated in positive mode ESI. The observed $\mathrm{m} / \mathrm{z}$ values were consistent with mass increase resulted from deimidation (460.3 for AA\{Cit\}AA and 459.3 for AARAA). A modest level of collision energy (CE, 25V) was applied and to leave a significant fraction of the precursor ion intact. During the optimization process, a range of $\mathrm{CE}$ was used and the resulting CID spectra were similar to those shown in Supplemental Figure 1 with only quantitative differences. For the citrullinated peptide, in addition to backbone cleavage products (b and y ions), several neutral loss ions were observed adjacent to the precursor ion. These include $-17 \mathrm{Da}$, corresponding to the loss of ammonia, and another peak at $-43 \mathrm{Da}$, whose identity was unpredicted. Upon inspection of the Cit structure, the identity of the -43 Da neutral loss was considered to be a carbamyl group, or isocyanic acid $(\mathrm{HN}=\mathrm{CO})$, a stable compound with boiling point of $23.5^{\circ} \mathrm{C}[25,26]$. The identity of the neutral loss species was subsequently confirmed by probing the structure of the -43 Da peak: an ornithine residue (Orn) is expected to be the product after loss of carbamyl group and $\mathrm{MS}^{3}$ analysis of the -43 ion showed that the other product was indeed AA\{Orn\}AA (Supplemental Figure 1 inset). $\mathrm{HN}=\mathrm{CO}$ loss also occurred on b3 and b4 ions, confirming the modification site. In contrast with fragmentation spectra from $\mathrm{AA}\{\mathrm{Cit}\} \mathrm{AA}$, only $\mathrm{NH}_{3}$ loss from AARAA

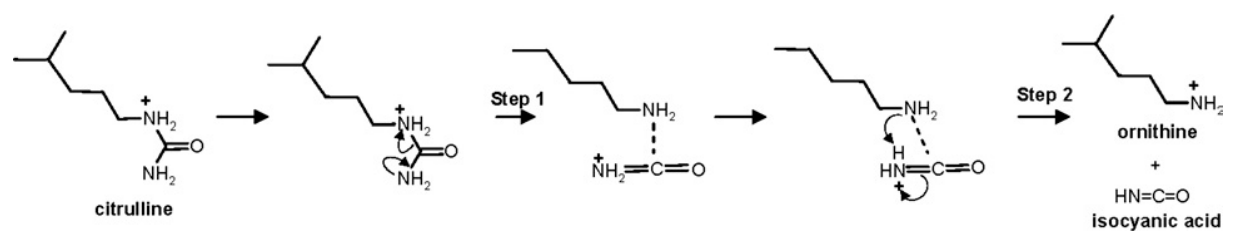

Scheme 1. Proposed fragmentation mechanism for isocyanic acid elimination from citrulline peptides. 


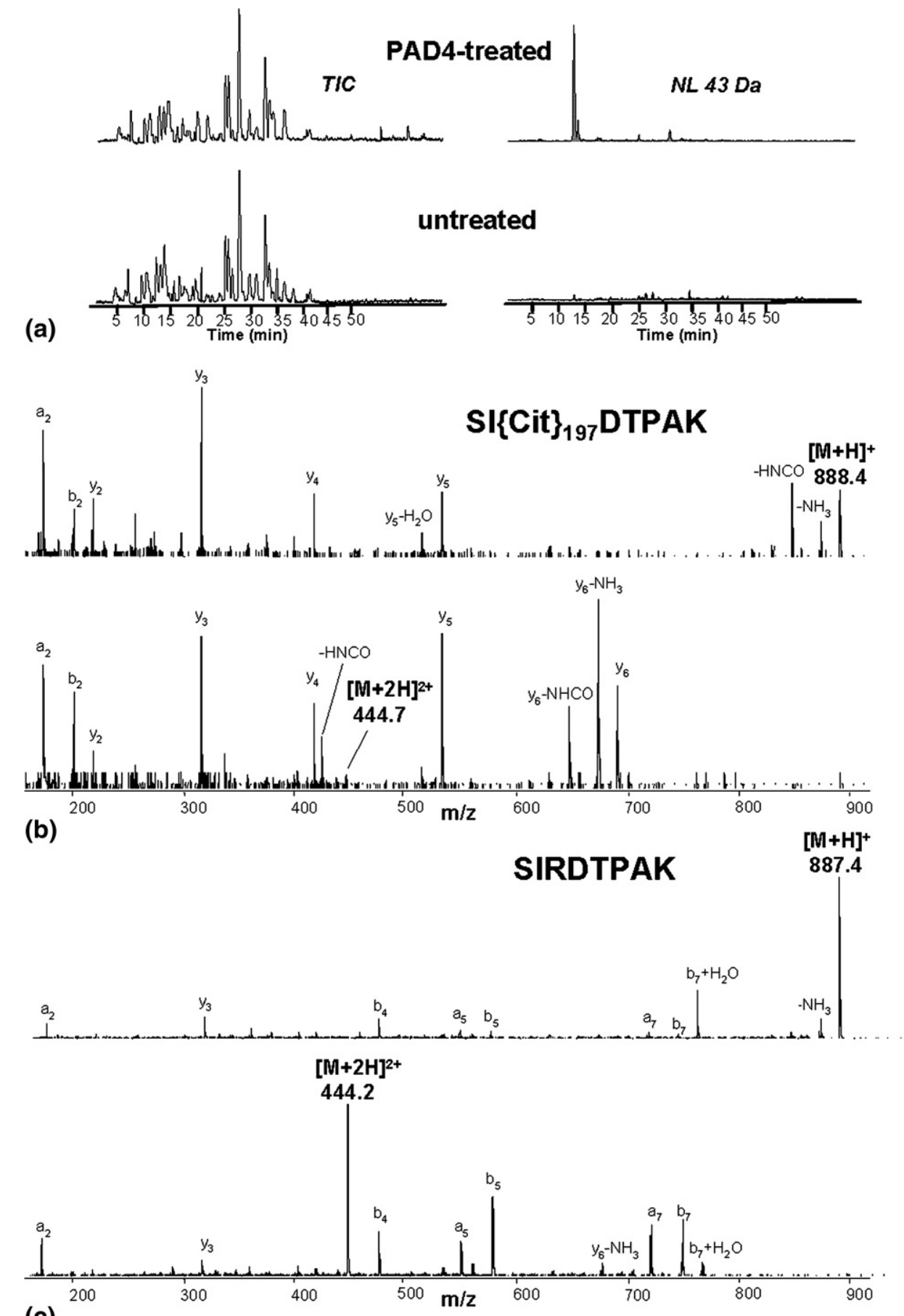

(c)

Figure 1. Identification of citrullination site in PAD-4 treated human nucleophosmin (NPM). Protein bands were in-gel digested with trypsin and resulting peptides were analyzed by LC-MS. Datadependant MS/MS scans were performed on the two most intense ions in each MS scan. The CID spectra were searched for neutral loss of 43 and $21.5 \mathrm{Da}$. A single peptide ion, corresponding to SI $\{$ Cit\}DTPAK containing Arg197 was found in PAD4-treated band. The observed $\mathrm{m} / \mathrm{z}$ was 888.4 for the singly-charged peptide ion and 444.7 for the doubly-charged species. The CE used for the peptide fragmentation was calculated using Analyst software (42 and 28 for singly- and doubly-charged ions, respectively.) (a) Total ion chromatograms (TIC) of PAD4-treated and untreated human NPM. The CID spectra were extracted to generate neutral loss spectra of 43 and 21.5 Da. Shown here is the $43 \mathrm{Da}$ neutral loss chromatogram that reveals a singly charged peptide SI $\{$ Cit $\}$ DTPAK eluted around $12 \mathrm{~min}$ in the PAD4-treated sample. The neutral loss chromatogram of 21.5 Da similarly identified the doubly charged precursor of the same citrullinated peptide (not shown). (b) and (c) CID spectra of the citrullinated peptide SI $\{$ Cit\}DTPAK and the native peptide SIRDTPAK. HNCO loss was abundant in CID spectra of both the singly and doubly charged citrullinated peptide ions, whereas only ammonia loss was found in the unmodified peptide spectra. 
was detected. The backbone fragmentation was also less prominent in AARAA as compared with AA $\{$ Cit $\} A A$, attributed to proton sequestering by the Arg residue in the former sequence.

A likely fragmentation mechanism for $\mathrm{HN}=\mathrm{CO}$ loss is depicted in Scheme 1. The reaction is proposed to proceed via two sequential steps. During the first step, protonation at the $\epsilon$ nitrogen of the citrulline side-chain induced $\mathrm{C}-\mathrm{N}$ bond fragmentation to initially yield an ion molecule complex between ornithine and $\left[\mathrm{OC}=\mathrm{NH}_{2}\right]^{+}$. In the second step, proton transfer within the ion molecule complex before its dissociation would then yield the protonated ornithine containing product ion and an isocyanic acid moiety.

To further investigate the fragmentation mechanism, a human histone $\mathrm{H} 4$ peptide (residues 15-26 containing Cit at positions 17, 19, and 23) $\mathrm{AK}\{\mathrm{Cit}\} \mathrm{H}\{\mathrm{Cit}\} \mathrm{KVL}\{\mathrm{Cit}\} \mathrm{DNIC}$ was selected as a model peptide. Notably, citrullination on histone proteins $\mathrm{H} 3$ and $\mathrm{H} 4$ is known to regulate their DNA-binding properties and mediate chromosome assembly $[3,14]$. The peptide carries an extra C-terminal cysteine residue for the purpose of carrier protein conjugation for antibody production. The synthetic $\mathrm{H} 4$ peptide exist in three charge states, $(+1,+2$, and +3 ), with molecular ions at $m / z$ of $1611.8,806.4$, and 538.0 for singly-, doubly- and triply-charged peptides, respectively. The CID spectra at CE of $45 \mathrm{~V}$ were shown in Supplement Figure 2. The singly-protonated peptide yielded predominantly a loss of $\mathrm{NH}_{3}, \mathrm{HNCO}$, two $\mathrm{HNCO}$, and combined losses of $\mathrm{NH}_{3}$ and $\mathrm{HNCO}$, consistent with multiple citrullination sites in the sequence. Minimum backbone cleavage was observed, in accord with the absence of a mobile proton in the sequence due to two Lys residues. For both doubly- and triply-charged peptide ions, HNCO loss is still prominent from both precursor ions and several intense $b$ ions. The doubly-charged peptide showed HNCO loss and some peptide bond cleavage ions, including b2, b3, $\mathrm{b} 7, \mathrm{~b} 8$, and b12 ions. The triply-charged peptide showed more peptide cleavage products, explained by the increased availability of mobile protons. These results suggest that HNCO elimination competes with backbone cleavage and readily occurs in both proton-mobile and fixed sequences.

We next tested whether the diagnostic HNCO could be used to identify an unknown citrullination site. Nucleophosmin (NPM) is a molecular chaperon involved in nucleosome core particle assembling [27]. It was shown previously that calcium ionophore triggers PAD4 dependent citrullination of NPM in HL-60 granulocytes [15], but the exact site was unidentified. In attempt to identify this citrullination site, we treated recombinant human His6-NPM with GST-PAD4 and analyzed the resulting deimination product. As shown in Supplement Figure 3a, PAD4 treatment leads to marked increase in citrulline level, as detected by anti-Cit Western blotting. The gel band was excised, subjected to trypsinolysis, resulting His6-NPM peptides (with and without PAD4 pretreatment) were analyzed by LC-MS and database searching. The total ion chromatograms (TIC) of tryptic digests of PAD4 treated and control NPM bands were shown in left panel of Figure 1a. The sequence coverage of database searching was greater than 95\% (Supplemental Figure 3b). The CID spectra were extracted for the neutral losses of 43 and $21.5 \mathrm{Da}$. The neutral loss chromatogram of $43 \mathrm{Da}$ was shown in the right panel of Figure 1a. A single prominent peak eluted around $12 \mathrm{~min}$ was detected in the neutral loss chromatogram of 43 Da for PAD4-treated band. The peak was derived from a singly-charged peptide ion with $\mathrm{m} / \mathrm{z}$ of 888.4 corresponding to tryptic peptide SI\{Cit\}DTPAK containing citrullinated Arg197. A similar result was obtained from neutral loss chromatogram of $21.5 \mathrm{Da}$, which revealed a doubly-charged ion at $\mathrm{m} / \mathrm{z} 444.7$ of the same peptide (data not shown). The CID spectra evidence HNCO loss from both the singly- and doubly-protonated peptides (see Figure 1b). The CID spectra of the unmodified peptide SIRDTPAK were acquired under the same collision energy (Figure 1c). In contrast to the citrullinated species, only $\mathrm{NH}_{3}$ loss from the precursor was observed. Intriguingly, the identified citrullination site is located in the vicinity of the ribonuclease activity center [28], suggesting a potential role for citrullination in the regulation of RNAsubstrate binding.

\section{Conclusions}

In summary, we demonstrate for the first time that gas-phase elimination of $\mathrm{HNCO}$ is an abundant feature of citrullinated peptides. The elimination occurs in both proton mobile and sequestered peptide precursor ions. Note that the Q Trap CID data resemble a quadrupole instrument as it is carried out in the collision cell and this dissociation was also prominently observed using an ion trap instrument (data not shown). The neutral loss should allow for post-acquisition searching of MS/MS data to discover novel citrullination sites. The incorporation of the side-chain loss into current search engines would increase the confidence of spectra matching and reduce the occurrence of false positive identifications. The technical advance should enable a more comprehensive identification of protein citrullination sites and aid in defining the roles of protein citrullination in health and disease.

\section{Acknowledgments}

The authors acknowledge support for this work by NIH grants RR019355-01, HL87062 to SSG and a Startup Fund from Pennsylvania State University to $\mathrm{YW}$.

\section{Appendix A Supplementary Material}

Supplementary material associated with this article may be found in the online version at 10.1016/ j.jasms.2008.12.012. 


\section{References}

1. György, B.; Tóth, E.; Tarcsa, E.; Falus, A.; Buzás, E. I. Citrullination: A Post-Translational Modification in Health and Disease. Int. J. Biochem. Cell. Biol. 2006, 38, 1662-1677.

2. Vossenaar, E. R.; Zendman, A. J.; van Venrooij, W. J.; Pruijn, G. J. PAD, a Growing Family of Citrullinating Enzymes: Genes, Features, and Involvement in Disease. Bioessays 2003, 25, 1106-1118.

3. Wang, Y.; Wysocka, J.; Sayegh, J.; Lee, Y. H.; Perlin, J. R.; Leonelli, L.; Sonbuchner, L. S.; McDonald, C. H.; Cook, R. G.; Dou, Y.; Roeder, R. G.; Clarke, S.; Stallcup, M. R.; Allis, C. D.; Coonrod, S. A. Human PAD4 Regulates Histone Arginine Methylation Levels via Demethylimination. Science 2004, 306, 279-283.

4. Li, P.; Yao, H.; Zhang, Z.; Li, M.; Luo, Y.; Thompson, P. R.; Gilmour, D. S.; Wang, Y. Regulation of p53 target gene expression by peptidylarginine deiminase 4. Mol. Cell. Biol. 2008, 28, 4745-4758.

5. Chavanas, S.; Méchin, M. C.; Nachat, R.; Adoue, V.; Coudane, F.; Serre, G.; Simon, M. Peptidylarginine Deiminases and Deimination in Biology and Pathology: Relevance to Skin Homeostasis. J. Dermatol. Sci. 2006, 44, 63-72.

6. Harauz, G.; Musse, A. A. A Tale of Two Citrullines-Structural and Functional Aspects of Myelin Basic Protein Deimination in Health and Disease. Neurochem. Res. 2007, 32, 137-158.

7. Sebbag, M.; Chapuy-Regaud, S.; Auger, I.; Petit-Texeira, E.; Clavel, C.; Nogueira, L.; Vincent, C.; Cornélis, F.; Roudier, J.; Serre, G. Clinical and Pathophysiological Significance of the Autoimmune Response to Citrullinated Proteins in Rheumatoid Arthritis. Joint Bone Spine 2004, 71, 493-502.

8. Ishigami, A.; Ohsawa, T.; Hiratsuka, M.; Taguchi, H.; Kobayashi, S.; Saito, Y.; Murayama, S.; Asaga, H.; Toda, T.; Kimura, N.; Maruyama, N. Abnormal Accumulation of Citrullinated Proteins Catalyzed by Peptidylarginine Deiminase in Hippocampal Extracts from Patients with Alzheimer's Disease. J. Neurosci. Res. 2005, 80, 120-128.

9. Ishida-Yamamoto, A.; Senshu, T.; Takahashi, H.; Akiyama, K.; Nomura, K.; Iizuka, H. Decreased Deiminated Keratin K1 in Psoriatic Hyperproliferative Epidermis. J. Invest. Dermatol. 2000, 114, 701-705.

10. Kinloch, A.; Lundberg, K.; Wait, R.; Wegner, N.; Lim, N. H.; Zendman, A. J.; Saxne, T.; Malmstr, V.; Venables, P. J. Synovial Fluid is a Site of Citrullination of Autoantigens in Inflammatory Arthritis. Arthritis Rheum. 2008, 58, 2287-2295.

11. Suzuki, A.; Yamada, R.; Yamamoto, K. Citrullination by Peptidylarginine Deiminase in Rheumatoid Arthritis. Ann. N.Y. Acad. Sci. 2007, 1108, 323-339.

12. Szekanecz, Z.; Soós, L.; Szabó, Z.; Fekete, A.; Kapitány, A.; Végvári, A.; Sipka, S.; Szücs, G.; Szántó, S.; Lakos, G. Anti-Citrullinated Protein Antibodies in Rheumatoid Arthritis: As Good as it Gets? Clin. Rev. Allergy Immunol. 2008, 34, 26-31.

13. Raptopoulou, A.; Sidiropoulos, P.; Katsouraki, M.; Boumpas, DT. Anticitrulline Antibodies in the Diagnosis and Prognosis of Rheumatoid Arthritis: Evolving Concepts. Crit. Rev. Clin. Lab. Sci. 2007, 44, 339-363.
14. Hagiwara, T.; Hidaka, Y.; Yamada, M. Deimination of Histone H2A and H4 at Arginine 3 in HL-60 Granulocytes. Biochemistry 2005, 44, 58275834.

15. Hagiwara, T.; Nakashima, K.; Hirano, H.; Senshu, T.; Yamada, M. Deimination of Arginine Residues in Nucleophosmin/B23 and Histones in HL-60 Granulocytes. Biochem. Biophys. Res. Commun. 2002, 290, 979-983.

16. Kidd, B. A.; Ho, P. P.; Sharpe, O.; Zhao, X.; Tomooka, B. H.; Kanter, J. L.; Steinman, L.; Robinson, W. H. Epitope Spreading to Citrullinated Antigens in Mouse Models of Autoimmune Arthritis and Demyelination. Arthritis Res. Ther. 2008, 10, R119 (doi:10.1186/ar2523).

17. Nachat, R.; Méchin, M. C.; Takahara, H.; Chavanas, S.; Charveron, M. Serre, G.; Simon, M. Peptidylarginine Deiminase Isoforms 1-3 are Expressed in the Epidermis and Involved in the Deimination of K1 and Filaggrin. J. Invest. Dermatol. 2005, 124, 384-393.

18. Kubota, K.; Yoneyama-Takazawa, T.; Ichikawa, K. Determination of Sites Citrullinated by Peptidylarginine Deiminase Using ${ }^{18} \mathrm{O}$ Stable Isotope Labeling and Mass Spectrometry. Rapid Commun. Mass Spectrom. 2005, 19, 683-688.

19. Nakayama-Hamada, M.; Suzuki, A.; Kubota, K.; Takazawa, T.; Ohsaka, M.; Kawaida, R.; Ono, M.; Kasuya, A.; Furukawa, H.; Yamada, R. Yamamoto, K. Comparison of Enzymatic Properties Between hPADI2 and hPADI4. Biochem. Biophys. Res. Commun. 2005, 327, 192-200.

20. Palumbo, A. M.; Tepe, J. J.; Reid, G. E. Mechanistic Insights into the Multistage Gas-Phase Fragmentation Behavior of Phosphoserine- and Phosphothreonine-Containing Peptides. J. Proteome Res. 2008, 7, 771779 .

21. Beausoleil, S. A.; Jedrychowski, M.; Schwartz, D.; Elias, J. E.; Villén, J. Li, J.; Cohn, M. A.; Cantley, L. C.; Gygi, S. P. Large-Scale Characterization of HeLa Cell Nuclear Phosphoproteins. Proc. Natl. Acad. Sci. U.S.A. 2004, 101, 12130-12135.

22. Brame, C. J.; Moran, M. F. McBroom-Cerajewski, L. D. A Mass Spectrometry Based Method for Distinguishing Between Symmetrically and Asymmetrically Dimethylated Arginine Residues. Rapid Commun. Mass Spectrom. 2004, 18, 877-881.

23. Gehrig, P. M.; Hunziker, P. E.; Zahariev, S.; Pongor, S. Fragmentation Pathways of N(G)-Methylated and Unmodified Arginine Residues in Peptides Studied by ESI-MS/MS and MALDI-MS. J. Am. Soc. Mass Spectrom. 2004, 15, 142-149.

24. Zou, Y.; Wang, Y. Tandem Mass Spectrometry for the Examination of the Post-Translational Modifications of High-Mobility Group A1 Proteins: Symmetric and Asymmetric Dimethylation of Arg25 in HMGA1a Protein. Biochemistry 2005, 44, 6293-6301.

25. Fischer, G.; Geith, J.; Klapötke, T. M.; Krumm, B. Synthesis, Properties, and Dimerization Study of Isocyanic Acid Z. Naturforschung 2002, 57b, $19-25$.

26. Voorhoeve, R. J.; Trimble, L. E. Synthesis of Isocyanic Acid from Nitric Oxide over Palladium and Iridium Catalysts. Science 1978, 202, 525-526.

27. Frehlick, L. J.; Eirín-López, J. M.; Ausió J. New Insights into the Nucleophosmin/Nucleoplasmin Family of Nuclear Chaperones. Bioessays 2007, 29, 49-59.

28. Hingorani, K.; Szebeni, A.; Olson, M. O. Mapping the Functional Domains of Nucleolar Protein B23. J. Biol. Chem. 2000, 275, 24451-24457. 